Original Research Article

\title{
Study of adverse drug reaction and causality assessment of antidiabetic drugs
}

\author{
Shanthi M. ${ }^{1 *}$, Madhavrao C. ${ }^{2}$
}

${ }^{1}$ Department of Pharmacology, Tirunelveli Medical College, Tamil Nadu, India ${ }^{2}$ Department of Pharmacology, Azeezia Medical College, Kollam, Kerala, India

Received: 05 September 2018

Revised: 24 November 2018

Accepted: 29 November 2018

\section{*Correspondence to:}

Dr. Shanthi M., Email: drshanthisenthilbabu@ gmail.com

Copyright: () the author(s), publisher and licensee Medip Academy. This is an openaccess article distributed under the terms of the Creative Commons Attribution NonCommercial License, which permits unrestricted noncommercial use, distribution, and reproduction in any medium, provided the original work is properly cited.

\begin{abstract}
Background: Study about adverse drug reaction of antidiabetic drugs helps in ensuring maximum benefits of drug therapy.

Methods: An observational study was carried out in patients attending tertiary care hospital in Kanyakumari district from August 2013 to August 2014. Adverse drug reactions due to the use of antidiabetic drugs were collected and adverse effects experienced by the patient was assessed using WHO scale, Naranjo scale, Schumock and Thornton scale and Hartwig and Siegel scale.

Results: In this prospective study a total of 76 adverse events (41 male and 35 female) were identified. Most frequently observed adverse effect were hypoglycaemia and the less observed were pruritis. Maximum of 14 adverse effect were observed due to use of insulin. Combination of sulphonylurea and biguanides caused 28 adverse effects. Assessment of adverse effect using WHO scale showed $64 \%$ as probable, $16 \%$ possible, $7 \%$ conditional, $5 \%$ unclassifiable, $4 \%$ certain, and $4 \%$ unlikely. Relationship of adverse reaction to antidiabetic drugs using Naranjo scale showed $92 \%$ possibly, $5 \%$ probably and $3 \%$ as definite. Antidiabetic drug adverse effects were not preventable in $63 \%$, definitely preventable in $19 \%$ and probably preventable in $18 \%$ as per modified Schumock and Thornton scale. Severity assessment of adverse effects were mild in $75 \%$, moderate in $25 \%$ and no severe reactions according to modified Hartwig and Siegel scale.

Conclusions: Adverse effect most commonly encountered during the study period were predictable, definitely preventable and without serious effects. Majority of the reactions were due to combination of antidiabetic drugs.
\end{abstract}

Keywords: Adverse drug reaction, Antidiabetic drugs, Causality assessment, Diabetes mellitus

\section{INTRODUCTION}

Diabetes mellitus (DM) prevalence is increasing globally. In India more than 65.1 million individuals have been diagnosed as diabetic and estimated to reach 79.4 million by 2030. ${ }^{1}$ Management of diabetes require both pharmacological and nonpharmacological intervention. Parenteral insulin and oral hypoglycaemic's are the available pharmacotherapy for this condition. An important factor deciding compliance of patient is the adverse effect.
Adverse drug reaction (ADR) is defined by World Health Organization (WHO)) as response to a drug which is noxious and unintended, and which occurs at doses normally used in man for prophylaxis, diagnosis or therapy of disease or for modification of physiological function. ${ }^{2}$ Knowledge about ADR of drugs helps in minimizing adverse effects associated with it. ADR has been recognized as a major limitation in providing health care. ${ }^{3}$ ADR accounts for repeated hospital admission and an important cause of morbidity. Identification of adverse reaction is lacking in studies conducted in India.2 ADR monitoring and reporting is in the stage of infancy in 
India. $^{4}$ In a study done in Indian ambulatory patients it was pointed out that $3.4-7 \%$ of hospitalization was due to ADR. ${ }^{5}$

Availability of new antidiabetic drugs and concern on patient safety emphasises the importance of conducting a study on ADRs. ${ }^{6}$ Monitoring ADR of antidiabetic drugs helps in providing continuous information on the safety of drug used. Evaluation of ADR is important for the assessment of risk factors to ensure maximum benefit of drug therapy. More data on prescribed drugs and their side effects will help in reducing the ADR occurrence and ensure patient safety.

\section{METHODS}

The present prospective study was conducted in department of Medicine, Sree Mookambika Institute of Medical Sciences, Kulasekharam, Kanyakumari district, Tamil Nadu over a period of one year (August 2013 to August 2014) to identify and assess the ADR. The ethical committee approval was obtained from Institutional Human Ethics Committee (IHEC).

\section{Inclusion criteria}

Adult diabetic patient aged 25 and above (both gender) treated with antidiabetic medicine.

\section{Exclusion criteria}

Subjects with history of drug abuse or intake of herbal drugs.

Patients on antidiabetic drugs attending outpatient department (OPD) of medicine who had or came for treatment of ADR were included in the study after getting written informed consent. Enrolled participants demographic details, history of diabetes, co-morbid condition, drug history collected and were interviewed regarding experience of any adverse effect following antidiabetic therapy. If the subject had experienced ADR suspected to be due to antidiabetic drugs, it will be recorded in the ADR reporting form. ADR details like the suspected drug, dose, route of administration, duration of therapy, time of initiation and duration of the adverse effect and its management were filled in the ADR form. ADRs were classified according to the drug class. All the ADRs were assessed using WHO scale, Naranjo scale, Modified Schumock and Thornton and Modified Hartwig and Siegel scale. Data collected were presented as number and percentages in tables and figures.

\section{RESULTS}

A total of 76 ADRs were reported out of which 41 noted in male and 35 in female study participant (Table 1). In this study systemic hypertension was the most frequently associated co-morbid condition as shown in Table 2. The other less common co-morbid conditions were chronic obstructive pulmonary disease (COPD), dyslipidemia, thyroid disorder, benign prostatic hypertrophy (BPH), cardiovascular disorder and depression.

Table 1: Gender wise distribution of adverse drug reaction.

\begin{tabular}{|lll|}
\hline Gender & n & \% \\
\hline Male & 41 & $53.94 \%$ \\
\hline Female & 35 & $46.05 \%$ \\
\hline
\end{tabular}

n: Number; \%: Percentage.

Table 2: Number and percentage of co-morbid conditions associated with DM.

\begin{tabular}{|lll|}
\hline Co-morbid condition & n & $\%$ \\
\hline Systemic hypertension & 62 & $71 \%$ \\
\hline $\begin{array}{l}\text { Chronic obstructive pulmonary } \\
\text { disease (COPD) }\end{array}$ & 7 & $8 \%$ \\
\hline Systemic hypertension with COPD & 6 & $7 \%$ \\
\hline Dyslipidemia & 3 & $4 \%$ \\
\hline Hypothyroidism & 3 & $4 \%$ \\
\hline Benign prostatic hypertrophy & 2 & $2 \%$ \\
\hline Cardiovascular disorder & 1 & $1 \%$ \\
\hline Hyperthyroidism & 1 & $1 \%$ \\
\hline $\begin{array}{l}\text { Systemic hypertension with } \\
\text { dyslipidemia }\end{array}$ & 1 & $1 \%$ \\
\hline Depression & 1 & $1 \%$ \\
\hline
\end{tabular}

n: Number; \%: Percentage.

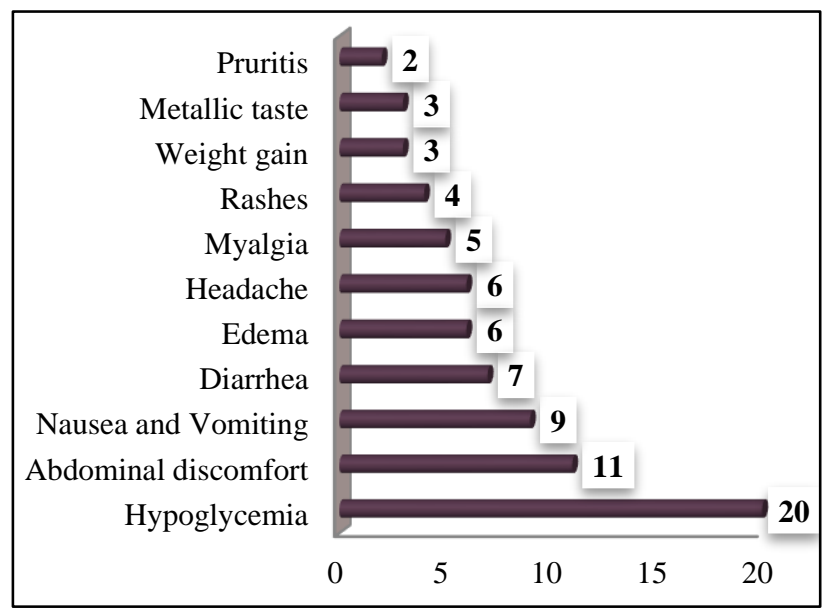

Figure 1: The adverse drug reactions reported due to antidiabetic drugs.

ADRs reported following treatment of DM with oral hypoglycaemic agents (OHA) and insulin is shown in Figure 1. ADRs shows hypoglycaemia in 20, abdominal discomfort in 11, nausea with vomiting in 9, diarrhea in 7 , edema in 6 , headache in 6 , myalgia in 5 , rashes in 4 , weight gain in 3 , metallic taste in 3 and pruritis in 2.

Maximum of 14 ADRs were reported with insulin. Drugs producing ADRs were thiazolidinediones (11), biguanides (11), sulphonylureas (5) and alpha glucosidase inhibitors 
(5) as represented in Figure 2. Combination of drugs producing ADRs are shown in Figure 3. 30 ADRs were reported due to combination antidiabetic therapy out of which 28 were due to sulphonylureas with biguanides and 2 were due to sulphonylureas with biguanides and thiazolidinediones.

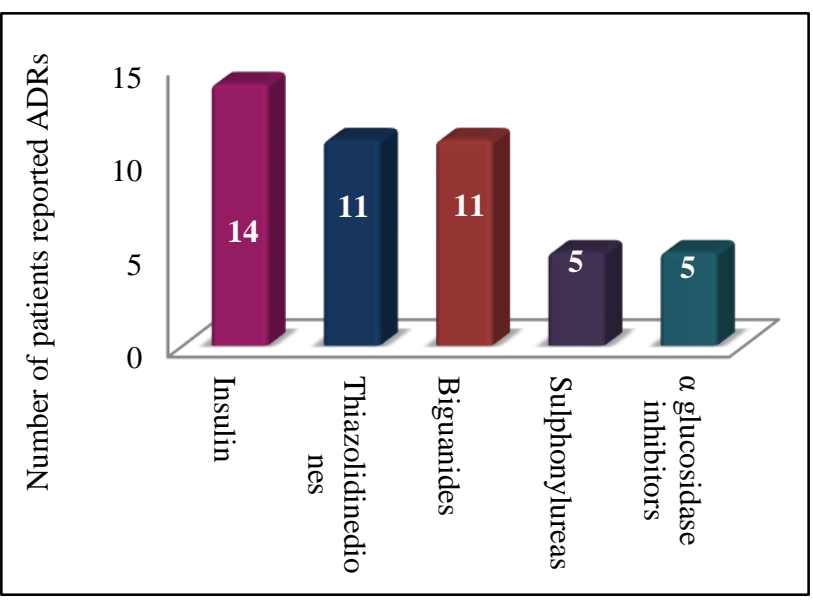

Figure 2: ADRs reported by patients due to different classes of antidiabetic drugs as monotherapy.

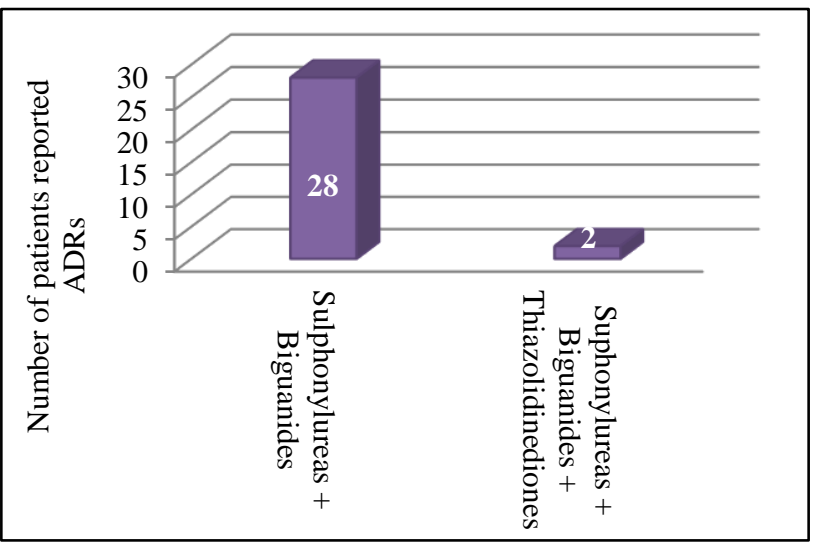

Figure 3: Number of ADRs reported due to antidiabetic drugs prescribed as combination therapy.

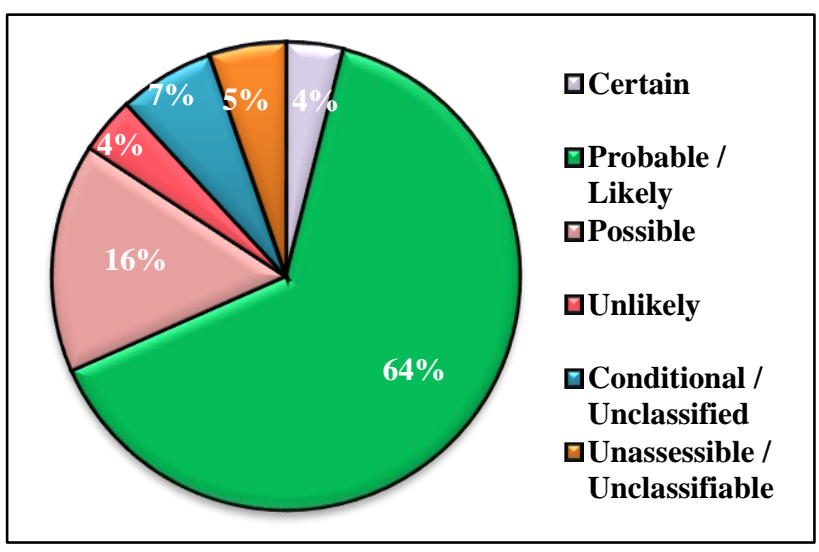

Figure 4: The percentage wise distribution of causality assessment of adverse drug reactions due to antidiabetic drugs by WHO scale.

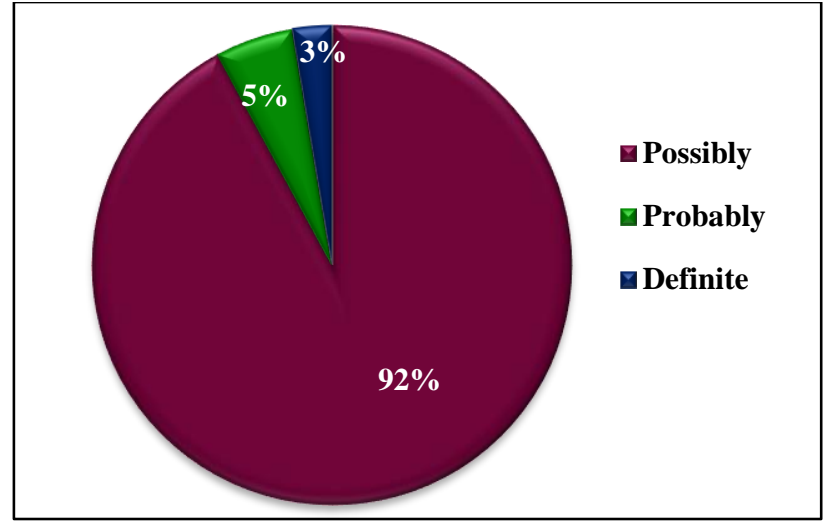

Figure 5: The percentage wise distribution of causative relationship of adverse drug reactions due to antidiabetic drugs by Naranjo scale.

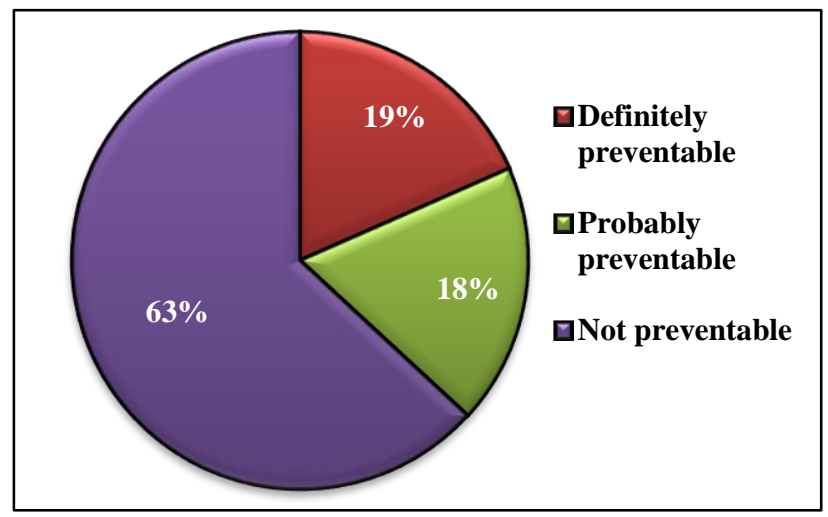

Figure 6: The percentage wise distribution of preventability of adverse drug reactions due to antidiabetic drugs by modified Schumock and Thornton scale.

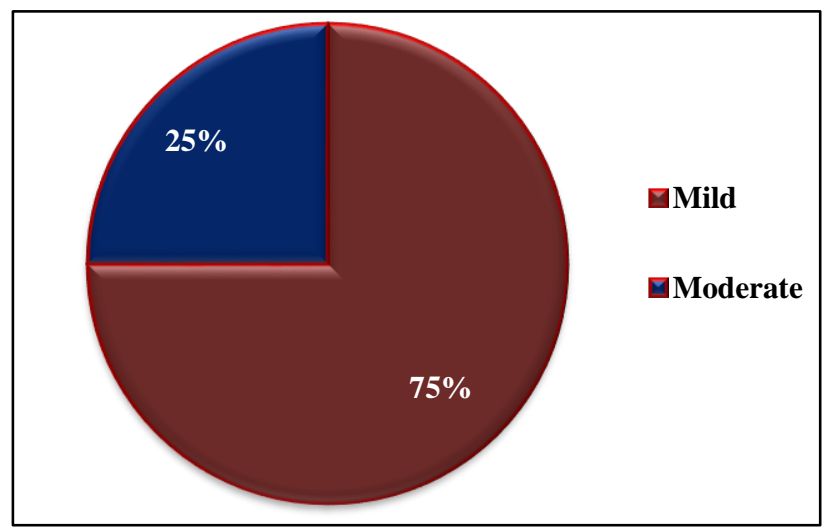

Figure 7: The percentage wise distribution of severity of adverse drug reactions due to antidiabetic drugs by modified Hartwig and Siegel scale.

Causality assessment of ADR due to antidiabetic drugs by WHO scale were probable in $64 \%$, possible in $16 \%$, conditional in $7 \%$, unclassifiable in $5 \%$, unlikely in $4 \%$ and certain in $4 \%$. This is represented as pie diagram in figure 4. Category of ADR according to the causative relationship 
to the drug administration by Naranjo scale is shown in the figure 5. Naranjo algorithm scoring categorised ADRs to be possible in $92 \%$ of the report. The remaining was probable $(5 \%)$ and definite $(3 \%)$. Preventability of ADR by modified Schumock and Thornton scale showed ADR to be definitely preventable in $19 \%$ of the reports. It was only probably preventable in $18 \%$ and not preventable $(63 \%)$ in the remaining as represented in Figure 6. Severities of ADRs using modified Hartwig and Siegel scale were mild in $75 \%$ of the patients and the others were moderate $(25 \%)$. In this prospective study no severe ADRs were reported as shown in Figure 7.

\section{DISCUSSION}

The present cross-sectional study established the adverse drug reaction profile and causality assessment of antidiabetic drugs in the outpatient department of Medicine, Sree Mookambika Institute of Medical Sciences, Kulasekharam, Kanyakumari district. A total of 169 prescriptions were analyzed during the study period. In this study 76 ADRs were reported (45 male and 31 female). This was comparable with the study conducted in a tertiary care hospital.

In the current study hypoglycaemia was the most commonly experienced ADR by the diabetic patients. Blood glucose level maintenance without inducing hypoglycaemia is important in reducing progressive complication with DM including risk of coronary vascular accident disease and death. Importance must be given while prescribing drugs for other co-morbid conditions. In this study systemic hypertension was the most common comorbid conditions seen in the diabetic patients. COPD, dyslipidemia, thyroid disorder, cardiovascular disorder, benign prostatic hypertrophy and depression were the other frequently observed co-morbid conditions. Increase report of hypoglycaemia could be due to inappropriate intake of drugs, inappropriate instructions followed or inappropriate intake of food by the patients. A nonpharmacological factor that could have contributed to development of hypoglycaemia may be stress. ${ }^{8}$ In this study the second most common ADR reported were gastrointestinal disturbances which is again in accordance with the previous study done on antidiabetic drugs. ${ }^{9}$

Assessment of ADRs helps in understanding the relationship of drug and the adverse effect, severity and preventability of the reactions reported. This can gain confidence and improve adherence to the treatment given. Our study showed that $64 \%$ of the ADRs were probable by using WHO causality assessment scale since the effect developed soon after the administration of drug and not due to concurrent disease or other drugs. $92 \%$ of the ADRs scored 1 to 4 by using Naranjo algorithm scale and hence categorised to be possible. In a similar study conducted in a tertiary care hospital $73.33 \%$ of ADR were found to be possible. ${ }^{10}$ Most of the ADRs were not preventable (63\%) as per modified Schumock and Thornton preventability scale. Only $10 \%$ of adverse effects were not preventable in a study conducted on antidiabetic patients. ${ }^{10}$ Hence appropriate dose according to the patient's requirement and appropriate instructions by the treating physician can prevent the ADRs. During the study no serious adverse drug reactions was reported. Most of the ADRs were mild to moderate in degree of severity as per modified Hartwig and Siegel scale. This is not in accordance to a study conducted in a hospital with 4 severe ADRs. ${ }^{10}$

Limitation of the study was small sample size. Period of study for a longer period could have made the significance of study more powerful. Study on interaction of drugs was not done in detail. These are the major drawback of the study. Appropriate medication and effective monitoring of ADR is the best way to safeguard the public. In a country like India with varied socioeconomic status, it is important to have a vigilant pharmacovigilance programme. This can improve adherence to therapy and prolong the time for development of microvascular and macrovascular complication thereby effectively reducing the morbidity and mortality.

\section{CONCLUSION}

In present study the ADRs were $64 \%$ probable by using WHO causality assessment scale. Naranjo algorithm scale assessed ADRs as possible in $92 \%$ of cases. Modified Schumock and Thornton scale for preventability of ADRs showed that $63 \%$ were not preventable. Modified Hartwig and Siegel scale for severity of ADRs showed that $75 \%$ of the ADRs reported were only mild and no severe ADRs reported. This study also found that combination of sulphonylureas with biguanides were responsible for most of the ADRs and among all the ADRs reported hypoglycaemia the commonest. ADR monitoring is essential to protect the diabetic patient from use of new antidiabetic drugs. Ensuring that risk in drug use are anticipated and can be managed by the treating physician will extend confidence in the health service provided. Hence can improve compliance and reduce hospital admission due to adverse effects.

\section{ACKNOWLEDGEMENTS}

Authors would like to thank the Department of Medicine for their cooperation to conduct the study.

Funding: No funding sources

Conflict of interest: None declared

Ethical approval: The study was approved by the Institutional Ethics Committee

\section{REFERENCES}

1. Ali H, Anwar M, Ahmad T, Chand N. Diabetes mellitus from antiquity to present scenario and contribution of Greco-Arab physicians. JISHIM. 2006;5(10):46-50.

2. Sharma H, Aqil M, Imam F, Alam MS, Kapur P, Pillai KK. A pharmacovigilance study in the department of 
medicine of a university teaching hospital. Pharmacy Practice. 2007 Mar;5(1):46-9.

3. Biswas P. Pharmacovigilance in Asia. J Pharmacol Pharmacother. 2013;4(5):7-19.

4. Alhat BR. Pharmacovigilance: an overview. Int J Res Pharm Chem. 2011;1(4):968-74.

5. Mandavi SD, Sachdev A, Tiwari P. Adverse drug reactions \& their risk factors among Indian ambulatory elderly patients. Indian J Med Res. 2012 Sep;136(3):404.

6. Ghewari PS, Salunkhe SS, Bhatia NM, Killedar SG, Chitranagari K. Strategies and current scenario of Pharamcovigilance in India. J Advanced Drug Delivery. 2014;1(3):122-34.

7. Akila L, Sandozi T, Geetha Devi AK, Kumar JS, Balasubramanian A, Jamuna Rani R. Drug utilization study of oral anti-diabetic drugs at a tertiary care (SRM Medical College) hospital in Chennai. Int J Med Res. 2011;1:177-82.
8. Viswanathan M, Joshi SR, Bhansali A. Hypoglycaemia in type 2 diabetes: Standpoint of an experts committee (India hypoglycaemic study group). Indian J Endocrinol Met. 2012;16(6):894-8.

9. Saravanan K, Manna PK, Mohanta GP, Manavalan R. A study of adverse drug reaction on drugs used in the management of type 2 diabetes mellitus. J Pharm Res. 2011;4(10):3394-5.

10. Palanisamy S, Kumaran KSGA, Rajasekaran A. A study on assessment, monitoring and reporting of adverse drug reactions in Indian hospital. Asian $\mathbf{J}$ Pharmaceutical Clin Res 2011;4(3):112-6.

Cite this article as: Shanthi M, Madhavrao C. Study of adverse drug reaction and causality assessment of antidiabetic drugs. Int J Basic Clin Pharmacol 2019;8:56-60. 